\title{
IMPACTO DA POLÍTICA CULTURAL PÚBLICA DE PORTO ALEGRE SOBRE AS ARTES VISUAIS
}

\author{
Denise Velloso Fernandes Ribeiro \\ Universidade Federal do Rio Grande do Sul \\ Instituto de Artes \\ Programa de Pós-Graduação em Artes Visuais
}

A política de apoio à cultura, em Porto Alegre, completou 18 anos, em 2006, fomentada, até a atualidade, pelo Funcultura e o Fumproarte. Entretanto, desde 1989, quando de sua implantação, pouco foi alterado nessa política. Ao longo dos anos foi perceptível um esforço da administração pública em cristalizar essas políticas através de leis municipais, institucionalizando-as. Tal atitude, em que pese garantir estabilidade e segurança, tanto aos administradores, quanto aos artistas e produtores culturais, acabou por tornar imutáveis os procedimentos de aplicação da política cultural, sem inovações ou revisões importantes. Assim, através deste trabalho, pretende-se examinar e avaliar a qualidade e a quantidade de recursos destinados às artes plásticas, no que concerne à validade, atualidade e coerência dessas aplicações, propondo, a partir do resultado das pesquisas, medidas e atitudes que visem ao aperfeiçoamento do processo.

"A cultura e as artes movimentam parte cada vez mais significativa da economia planetária. As indústrias criativas não param de crescer para alimentar uma demanda, que parece inesgotável, por estética, símbolos, lazer, entretenimento e ascendência" (SARKOVAS, 2006)1. Os recursos gerados por este vasto mercado de consumo, entretanto, não suprem a diversidade e a complexidade cultural brasileira. No Brasil, estudos realizados há alguns anos pela Fundação João Pinheiro, indicaram que a economia da cultura representa, pelo menos, $2 \%$ do PIB nacional, ou seja, movimenta pelo menos 1 bilhão de dólares/ano (dados de 2001) ${ }^{2}$.

As leis de incentivo à cultura se tornaram, ao longo dos últimos anos, o grande veículo para que produtores culturais de todo o país conseguissem viabilizar seus projetos. Por outro lado, a área da cultura

1 SARKOVAS, Yacoff. O incentivo fiscal à cultura no Brasil. Disponível em www.artes.com Acesso em: julho de 2006.

${ }^{2}$ MINISTÉRIO DA CULTURA. Disponível em www.cultura.gov.br Acesso em: julho de 2006. 
tende a ser vista como acessória no conjunto das políticas governamentais, qualquer que seja a instância administrativa. Quase sempre são os militantes da área cultural os únicos a defender a idéia de que a cultura transcorre em todos os aspectos da vida da sociedade e de que, sem ela, os planos de desenvolvimento sempre serão incompletos e fadados ao insucesso. (FARIA e SOUZA, 1993) ${ }^{3}$.

No Brasil, explica Botelho (2006)4, "há bons exemplos de políticas democráticas desencadeadas por governos municipais e o maior ganho, deste comprometimento, foi o de ter ampliado a visibilidade da área cultural na maioria destas gestões, o que não significa ganhos de natureza propriamente cultural". Quando a Frente Popular ${ }^{5}$ assumiu a administração de Porto Alegre, em 1989, o único mecanismo de financiamento para a cultura era o Funcultura, que viabilizava exclusivamente projetos de iniciativa do Poder Público. Buscando estimular a produção cultural da capital gaúcha, nas mais diversas artes, nasceu o Fumproarte, criado pela Lei 7328/93, regulamentado pelo Decreto 10867/93 e em funcionamento desde janeiro de 1994.

Com o objetivo de criar um mecanismo essencialmente democrático na escolha de projetos que receberiam verbas públicas, permitindo que os impostos dos cidadãos retornassem sob a forma de produto cultural, evitando clientelismos ou favorecimentos, a forma administrativa criada foi um comitê assessor, que verifica o cumprimento das regras dos editais e um comitê de avaliação e seleção que analisa as propostas em reuniões abertas ao público. Ao longo de 18 anos, foi perceptível um esforço da administração pública em cristalizar essas políticas através de leis municipais, institucionalizando-as. Tal atitude, em que pese garantir estabilidade e segurança, tanto aos administradores, quanto aos artistas e produtores culturais, acabou por sedimentar uma política cultural estática, sem espaço para o novo. Através de metodologia adequada, pretende-se pesquisar, examinar a qualidade e a quantidade de recursos destinados às artes plásticas, tentando determinar validade,

${ }^{3}$ FARIA, H.J.B. de e SOUZA, V. de (orgs.). Experiências de gestão cultural democrática. São Paulo: Pólis, 1993.

${ }^{4}$ BOTELHO, Isaura. Dimensões da Cultura e Políticas Públicas. Disponível em www.scielo.br Acesso em: julho de 2006.

${ }^{5}$ Frente Popular foi uma coligação dos partidos de esquerda, formada pelo Partido dos Trabalhadores, Partido Comunista Brasileiro, Partido Verde e Partido Socialista Brasileiro, vencedora das eleições de 1989, para a Prefeitura Municipal de Porto Alegre. 
atualidade e coerência dessas aplicações. Tendo em vista as particularidades das formas de produção, comercialização e exibição da área das artes plásticas, esse estudo cresce de importância na medida em que poderá propor medidas e atitudes que visem ao aperfeiçoamento do processo.

O Fumproarte investe, diretamente, recursos em projetos de natureza artístico-cultural, explica Tomasi $(2006)^{6}$ e foge da lógica das Leis de Incentivos que trabalham com renúncia fiscal, pois é um Fundo que se destina a apoiar projetos das mais diversas áreas da cultura e disponibilizar o acesso da população aos mesmos. As reuniões de análise do mérito dos projetos é aberta ao público, sendo oportunizado ao proponente fazer a defesa oral de seu projeto. Além disso, os projetos devem ter objetivos afins ao interesse público, sendo a população a maior beneficiada. O Fundo, segundo Tomasi (2006) ${ }^{7}$, tem conseguido atingir seu objetivo de estimular a produção artístico-cultural de Porto Alegre, investindo não só em artistas consagrados, como naqueles que estão iniciando a vida artística. Nos primeiros 10 anos de Fumproarte, o valor

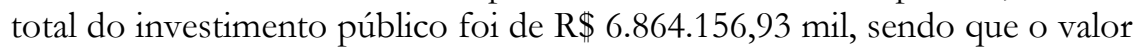
destinado às artes plásticas foi de $\mathrm{R} \$ 477.541,34$. Valor baixo se comparado à música (contemplada com $\mathrm{R} \$ 1.997 .344,25)$ ou com o teatro ( $\mathrm{R} \$$ $1.962 .620,32)^{8}$.

De acordo com Bocatto (2006), [...] as leis de incentivo à cultura se tornaram, ao longo dos últimos anos, o grande veículo para que produtores culturais brasileiros conseguissem viabilizar seus projetos. Com a falência financeira do Estado nacional, os mecanismos de apoio direto à produção cultural foram se tornando cada vez mais escassos. A cultura teve de buscar alternativas para sobreviver. A solução para o problema apontava para uma maior aproximação dos produtores culturais com a iniciativa privada. As leis de incentivo foram o caminho escolhido (BOCATTO, 2006) ${ }^{9}$.

As leis de incentivo oferecem benefício fiscal (à pessoa física ou jurídica) como atrativo para investimentos em cultura. Existem, hoje, leis de

\footnotetext{
${ }^{6}$ TOMASI, Elizabete. Fundo Municipal De Apoio À Produção Artística E Cultural De Porto Alegre Fumproarte. Disponível em nutep.adm.ufrgs.br/projetos/projportoalegre.htm\#7. Acesso em: agosto de 2006.

${ }^{7}$ TOMASI, op. cit., 2006.

8 SECRETARIA MUNICIPAL DA CULTURA. Fumproarte 10 Anos. Porto Alegre, Editora Pallotti, 2003.

9 BOCATTO, Paulo. A era dos incentivos fiscais. Disponível em www.telaviva.com.br/leis/main.htm Acesso em: julho de 2006.
} 
incentivo federais, estaduais e municipais. Dependendo da lei utilizada, o benefício pode chegar até a $100 \%$ do valor do projeto e $20 \%$ do imposto devido. Vale salientar que cada lei tem seu funcionamento específico, ou seja, as leis federais oferecem isenção no Imposto de Renda das pessoas físicas ou jurídicas; as estaduais proporcionam isenção de ICMS; e as municipais, de IPTU e ISS. Algumas optam por financiar a fundo perdido ou fazer empréstimos a projetos culturais regionais.

Existem outros mecanismos de aporte, porém, apesar da existência deles, sem o apoio de pelo menos uma das leis de incentivo, dificilmente o artista e/ou produtor consegue levar seu projeto adiante. Formatar projetos para inscrição nas leis exige tempo e dinheiro. Pode-se perceber, também, que o planejamento dos governos locais raramente inclui uma política municipal de cultura. O setor cultural é visto como ações ou programas desarticulados (oficinas, exposições, bienais, festivais, etc.) e não é considerado constitutivo da vida das comunidades, tampouco fundamental para o desenvolvimento social e cultural e a melhoria da qualidade de vida.

Em Porto Alegre, há 18 anos, a Frente Popular criou o Fumproarte - Fundo Municipal de Apoio à Produção Artística e Cultural de Porto Alegre (até então só havia o Funcultura). Criado em janeiro de 1994, o Fumproarte, em seus primeiros dez anos de existência, financiou 358 projetos nas áreas de teatro, artes plásticas, cinema, vídeo, música, literatura, memória cultural, artesanato, fotografia, dança e folclore. $\mathrm{O}$ valor financiado chegou a $\mathrm{R} \$ 6.864$ mil, com recursos orçamentários da prefeitura.

A lei não prevê incentivos fiscais, nem a participação de empresas. O modelo adotado pelo Fumproarte é do financiamento direto, diferenciado da maioria das leis de incentivo brasileiras, que operam com a lógica da renúncia fiscal. A escolha dos projetos beneficiados se dá através de concurso público, por intermédio de uma comissão composta por dois terços de representantes eleitos pela comunidade cultural; e dois terços de técnicos indicados pela SMC (Secretaria Municipal de Cultura).

De acordo com a UNESCO (Organização das Nações Unidas para a Educação, a Ciência e a Cultura ${ }^{10}$, cultura pode ser entendida como um

${ }^{10}$ Definição conforme as conclusões da Conferência Mundial sobre as Políticas Culturais (Mondiacult, México, 1982), da Comissão Mundial de Cultura e Desenvolvimento (Nossa Diversidade Criativa, 1995) e da Conferência Intergovernamental sobre Políticas Culturais para o Desenvolvimento (Estocolmo, 1998). 
conjunto de características distintas, espirituais, materiais, intelectuais e afetivas que caracterizam uma sociedade ou um grupo social. Engloba, além das artes e das letras, os modos de vida, os sistemas de valores, as tradições e as crenças. No caso deste trabalho de pesquisa, o foco estará nas relações comerciais, geração de negócios e renda (produção, circulação, preservação, etc), através de incentivos públicos, ligados às artes plásticas.

Brant $(2004)^{11}$ explica que, encarar uma manifestação cultural como produto, faz sentido quando ela é vista dentro de seu vasto espectro sociocultural, com foco em seu potencial econômico direto. Para o autor, na visão individual do artista, "a arte não tem necessariamente de passar por um processo de sustentação sociológica". Alguns argumentos a favor do comportamento de mercado, em relação à atividade cultural, podem ser arriscados e o primeiro deles é a situação atual de globalização mundial, voltada para as relações de economia de mercado, quando o entretenimento é satisfeito através do consumo.

Para Reis (2003) ${ }^{12}$, Políticas Culturais formam um conjunto de valores, princípios, instrumentos e atitudes que guiam a ação do governo na condução das questões culturais. Para a autora, por mais ativa que possa ser uma ação privada, a política pública da cultura, assim como a da economia ou a da educação, acaba definindo uma linha-mestra que delimita o próprio espaço deixado à complementaridade da ação do setor privado, inibindo-a ou incentivando-a.

Na definição de Brant (2004) para Políticas Culturais, lê-se: [...] um programa de intervenções realizadas pelo Estado, instituições civis, entidades privadas ou grupos comunitários com o objetivo de satisfazer as necessidades culturais da população e promover o desenvolvimento de suas representações simbólicas (BRANT, 2004) ${ }^{13}$. Por outro lado, nenhuma ação de política cultural findará vitoriosa se não estimular a riqueza da diversidade de suas produções e o livre acesso da população a qualquer nota dessa "grande sinfonia", como expressa Reis (2003). Em outras palavras, [...] não se pode gostar do que não se conhece. Assim, a política cultural não deveria estimular as pessoas a adquirir o gosto por um tipo de

${ }^{11}$ BRANT, Leonardo. Mercado Cultural: Panorama crítico e guia prático para gestão e captação de recursos. São Paulo: Escrituras Instituto Pensarte, 2004, p.39.

12 REIS, Ana Carla Fonseca. Marketing Cultural e Financiamento da Cultura. São Paulo: Pioneira Thomson Learning, 2003, p.139.

${ }^{13}$ BRANT, op. cit., 2004, p.57. 
arte, mas sim oferecer-lhes a oportunidade de experienciar diversas formas de manifestações artísticas.

A falta de recursos, entretanto, é uma das principais dificuldades enfrentadas tanto por aqueles que estão envolvidos na gestão da política cultural, quanto pelos que estão empenhados na produção cultural. Os governos enfrentam uma crônica falta de recursos para investimentos, o que impede a ampliação do orçamento das áreas de cultura como seria desejado. É fundamental a criação de formas para captar recursos que atraiam investidores e patrocinadores, dinamizando a produção cultural no município, sem provocar sobrecarga e aproveitando mais eficazmente o potencial dos produtores, sem depender, necessariamente, de verbas estaduais e federais. Para Fonseca (2006) ${ }^{14}$, a cultura, no Brasil, ainda é dependente das leis de incentivo, uma vez que o mercado não consegue sobreviver sem elas. Os projetos culturais precisam estar nelas aprovados como condição mínima para captar recursos junto às empresas. E estas raramente patrocinam a cultura se não puderem usufruir os benefícios fiscais.

Já de acordo com Yacoff Sarkovas (in Wander, 2005) o processo é crítico: [...] a incapacidade e até mesmo a perversidade do sistema de leis de incentivo baseadas em renúncia fiscal é uma noção que cresce de maneira inversamente proporcional à capacidade dos agentes públicos de mudá-lo. Além de perversas, as leis de incentivo são perdulárias, injustas e deseducam o empresariamento no trato do apoio cultural. [...] Mudar a lei não é mexer em dois, três artigos dela, mas mudar o sistema de financiamento público à cultura. É fazer com que se substitua o sistema de dedução fiscal por um sistema de fundo de financiamento público e, a médio prazo, desaparecer com as leis de renúncia fiscal (SARKOVAS in WANDER, 2005) ${ }^{15}$.

Nas últimas décadas, alguns municípios iniciaram a aplicação de leis de incentivo fiscal à produção cultural. O princípio adotado é da renúncia da prefeitura de arrecadar impostos em valores correspondentes ao total ou a parcelas dos valores de investimentos, ou patrocínios em

14 FONSECA, André. A ditadura das leis de incentivo. Artigo datado de 20 de julho de 2006. Disponível em www.culturaemercado.com.br. Acesso em: julho de 2006.

15 WANDER, Edson. O sistema injusto das leis de incentivo à cultura. Artigo datado de 24 de maio de 2005. Disponível em www.culturaemercado.com.br/setor.php?setor=2\&pid=601Acesso em: julho de 2006. 
produções culturais. Para Natale e Olivieri $(2003)^{16}$, as várias leis de incentivo federais, estaduais e municipais adotam o mesmo modelo para concessão de incentivo fiscal, em que a apresentação do produto cultural é mais valorizada que a sua criação ou concepção (o que, no caso das artes plásticas, é seguidamente a etapa mais onerosa).

As leis de incentivo fiscal à cultura, como regra geral, na modalidade mecenato ${ }^{17}$, apóiam o desenvolvimento e a realização de projetos que, necessariamente, resultem em bem cultural, por exemplo: um livro, um espetáculo, uma exposição, etc. Dessa forma, não é possível obter o apoio dessas leis para realização de pesquisa que objetive apenas o aprimoramento artístico do proponente ou de um grupo, sem a materialização em um produto cultural final, que possa ser desfrutado pelos cidadãos (NATALE e OLIVIERI, 2003, p.66) ${ }^{18}$.

De acordo com Souza e Faria $(1998)^{19}$, o mercado de consumo de bens e serviços culturais e o circuito de distribuição dos produtos culturais (teatros, salas de exposição, bibliotecas, auditórios) se desenvolvem e os grupos produtores de cultura encontram apoio. A ênfase deste tipo de ação está na cultura ao alcance de todos. Isso pode ser conseguido com a realização de shows públicos, ingressos a preços mais baratos, espetáculos teatrais abertos ao público, facilidade de acesso aos equipamentos culturais, como galerias e espaços de exposições.

Os mesmos autores asseveram, ainda, que uma das maiores dificuldades, ao se tentar elaborar uma política cultural para o município, é convencer o conjunto do governo da necessidade de se considerar a cultura como prioritária na gestão pública e não uma atividade menor em relação a outras necessidades da população. Outro problema é estabelecer recursos próprios para implementar a política cultural planejada. Os gestores culturais dos municípios se ressentem muito da falta de informações sobre financiamento a projetos culturais.

Os Estados e municípios brasileiros lançaram mão de suas próprias leis de incentivo à cultura, como instrumentos de políticas culturais mais ou

\footnotetext{
${ }^{16}$ NATALE, Edson; OLIVIERI, Cristiane. Guia Brasileiro de Produção Cultural 2004. São Paulo: Zé do Livro, 2003.

17 incentivo a projetos culturais

${ }^{18}$ NATALE; OLIVIERI, op. cit., 2003, p.66.

${ }^{19}$ SOUZA, Valmir de; FARIA, Hamilton. Política Municipal de Cultura. Publicado originalmente como DICAS no 116 em 1998. BNDES Disponível em www.federativo.bndes.gov.br. Acesso em: julho de 2006
} 
menos bem-definidas. "A beleza das iniciativas estaduais e municipais estaria, conceitualmente, na complementaridade à linha de atuação federal, por conhecer com propriedade única o contexto, as necessidades e a cultura de cada região" (REIS, 2003, p. 188) ${ }^{20}$.

\section{Bibliografia}

BRANT, Leonardo. Mercado Cultural: Panorama crítico e guia prático para gestão e captacão de recursos. São Paulo: Escrituras Instituto Pensarte, 2004.

FARIA, H.J.B. de e SOUZA, V. de (orgs.). Experiências de gestão cultural democrática. São Paulo: Pólis, 1993. MALHOTRA, N. K. Pesquisa de Marketing: uma orientação aplicada. Porto Alegre: Bookman, 2001.

MATTAR, Fauze Nagib. Pesquisa de Marketing: metodologia, planejamento. São Paulo: Atlas, 1999.

NATALE, Edson; OLIVIERI, Cristiane. Guia Brasileiro de Produção Cultural 2004. São Paulo: Zé do Livro, 2003.

REIS, Ana Carla Fonseca. Marketing Cultural e Financiamento da Cultura. São Paulo: Pioneira Thomson Learning, 2003.

ROESCH, Sylvia Maria Azevedo. Projetos de estágio e de pesquisa em administração: guia para estágios, trabalhos de conclusão, dissertações e estudo de caso. São Paulo: Atlas, 1999.

SECRETARIA MUNICIPAL DA CUlTURA. Fumproarte 10 Anos. Porto Alegre, Editora Pallotti, 2003.

VERGARA, Sylvia Constant. Projetos e relatórios de pesquisa em administração. São Paulo: Atlas, 2000.

\section{E, na Internet:}

BOCATTO, Paulo. A era dos incentivos fiscais. Disponível em www.telaviva.com.br. Acesso em: julho de 2006

BOTELHO, Isaura. Dimensões da Cultura e Politicas Públicas. Disponível em www.scielo.br Acesso em: julho de 2006.

BRAGA, Amaro. Editor do Guia de Artes Plásticas na Internet. Disponível em www.sobresites.com/artesplasticas Acesso em: julho de 2006

FONSECA, André. A ditadura das leis de incentivo. Disponível em www.culturaemercado.com.br Acesso em: julho de 2006

LAUERMANN, Martha; DEROSSO, Simone; CANAZARO, Carolina; CAMPELO, Thaís. FUMPROARTE - A Visão da Comunidade Cultural de Porto Alegre. Relatório de Pesquisa (2005). Portal Iberoamericano de Gestión Cultural. Disponível em www.gestioncultural.org. Acesso em: agosto de 2006

MINISTÉRIO DA CULTURA. Disponível em www.cultura.gov.br Acesso em: julho de 2006.

SARKOVAS, Yacoff. O incentivo fiscal à cultura no Brasil. Disponível em www.artes.com Acesso em: julho de 2006.

\footnotetext{
${ }^{20}$ REIS, op. cit., 2003, p. 188.
} 
SENNA, Letícia. Fumproarte: um "empurrãozinho" (fundamental) para a cultura porto-alegrense. Disponível em www. portoalegre.rs.gov.br Acesso em: agosto

SOUZA, Valmir de; FARIA, Hamilton. Política Municipal de Cultura. Publicado originalmente como DICAS no 116 em 1998. BNDES Disponível em www.federativo.bndes.gov.br Acesso em: julho de 2006

PORTAL DO FUMPROARTE. Disponível em portoalegre.rs.gov.br Acesso em: agosto de 2006

TEIXEIRA, José. Medalha Contemporânea - Formas e Teoria Artística. Disponível em www.escultor.com.pt Acesso em: julho de 2006.

TOMASI, Elizabete. Fundo Municipal De Apoio À Produção Artística E Cultural De Porto Alegre - Fumproarte. Disponível em nutep.adm.ufrgs.br Acesso em: agosto de 2006.

VAZ, José Carlos. Lei de Incentivo à Cultura. Publicado originalmente como DICAS no 43 em 1995. BNDES Disponível em www.federativo.bndes.gov.br Acesso em: julho de 2006.

Catálogos de exposições de arte e outros materiais gráficos oriundos de projetos financiados pelo Fumproarte. 